Quebec Cooperative Study

of Friedreich's Ataxia

\title{
Brain Lesions in Friedreich's Ataxia
}

\author{
D. R. OPPENHEIMER
}

SUMMARY: An estimate is given of the frequency of pathological changes (assessed bi cell populations and from myelin staining) in the brains of 15 cases of Friedreich's ataxia. Mention is made of the special problem of distinguishing primar!' degenerative lesions from those due to circulatory disturbances arising from the patients cardiac disease.

RÉSUMÉ: Nous présentons un estimé de la fréquence des modifications pathologiques (mesurées par l'étude des populations cellulaires et grâce aux colorations de la myéline), dans le cerveau de 15 patients atteints d'ataxie de Friedreich. Nous mentionnons le problème spécial qui consiste à distinguer les lésions dégénératives primaires de celles dues à des troubles circulatoires secondaires à la maladie cardiaque du patient.

From The Department of Neuropathology, Radcliffe Infirmary, Oxford, England.

Reprint requests for the complete supplement on Friedreich's Ataxia (Phase Two, Part Two) to:

Dr. André Barbeau, Clinical Research Institute of Montreal, 110 Pine Avenue West, Montreal, Quebec, Canada, H2W 1R7

\section{INTRODUCTION}

The findings reported here were to have appeared in a comprehensive survey of the pathology of Fried reich's ataxia. Work on this was halted in 1971 by a fire which destroyed the pathological material, including histological preparations, clinical notes, and other documents and photographs. The material had been amassed mainly as a result of the enthusiasm of a clinical neurologist, Dr. R. L. Hewer, who worked in the Oxford Neuropathology Department in 1967 and 1968. A collaborative study of the peripheral nerves in Friedreich's ataxia (Hughes, Brownell and Hewer, 1968), based on 18 necropsy and 4 biopsy cases, was to have been followed by a study of the central nervous system based on the findings in 22 cases, in all of which we had examined the spinal cord and in 15 of which brain tissue - the whole brain, or parts of it - was available. In every case there was good evidence that the clinical course had been that of "classical" Friedreich's ataxia (onset before the age of 20, abnormal E.C.G., etc.). It was intended that Dr. Brownell, Dr. Hughes and I should each examine the material independently, and publish only those findings on which we agreed. In the first place, Dr. Hughes examined the cords, and I the brains. Dr. Hughes detailed record of his findings was destroyed, along with the specimens, by the fire. I have his authority for saying that the differences from case to case were quantitative, not qualitative; in every case there was severe loss of fibers in the gracile funiculi and pyramidal and dorsal spino-cerebellar tracts, with less severe lesions in the cuneate fasciculi and ventral spino-cerebellar tracts; the cells of the thoracic (Clarke's) nucleus were severely reduced or absent in every case; and in no case was there detectable loss of anterior horn cells (Fig. 1).

At the time of the fire, Dr. Brownell and Dr. Hewer had both taken consultant appointments at the Frenchay Hospital in Bristol. I had sent them typed summaries of my findings in the brains, which are reproduced here. Unfortunately, there was no record of the findings in individual cases, so that no correltion of clinical and pathological data was possible - for instance correlation of visual failure with optic nerve degeneration. Although most of the clinical notes were destroyed, Dr. Hewer had kept records of the main features of 13 of the 15 cases, which are summarized in Table 1. Some of the brains were received incomplete, and in some cases we received only histological blocks, the fixed tissue having been discarded. I therefore recorded my observations in the form of fractions, in which the denominator represented the number of specimens examined.

Standard brain cutting and staining techniques were used throughout this study.

\section{RESULTS}

1. Sensory System (Fig. 2)

a) Primary neurons (judged by myelin staining): Pallor of entering roots trigeminal nerves in $8 / 9$. Pallor of descending trigeminal tracts in $11 / 15$. Pallor of glossopharyngeal and/or vagus in 7/13. Pallor of solitary tracts in $7 / 15$.

b) Secondary neurons (judged by Nissl, Holzer and myelin stains): Gracile and cuneate nuclei densely gliotic in 13/13 (gracile always worse than cuneate). Cell loss hard to judge. Seen in gracile nucleus in $9 / 13$, in cuneate nucleus in 2/13. Medial fillet: wasting and myelin pallor in ventral (gracile) portion in $12 / 15$. Not 


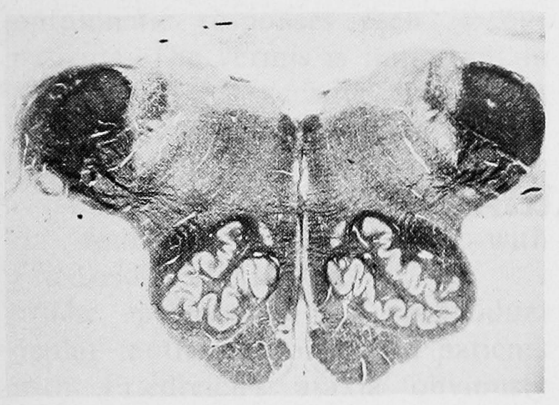

Figure 1 -Characteristic appearance of lower cervical cord in Friedreich's ataxia. The posterior columns are shrunken. There is loss of myelin in the posterior columns (gracile more than cuneate), spino-cerebellar tracts (posterior more than anterior), and crossed and uncrossed corticospinal tracts. Male: age at onset 7; age at death 25 .

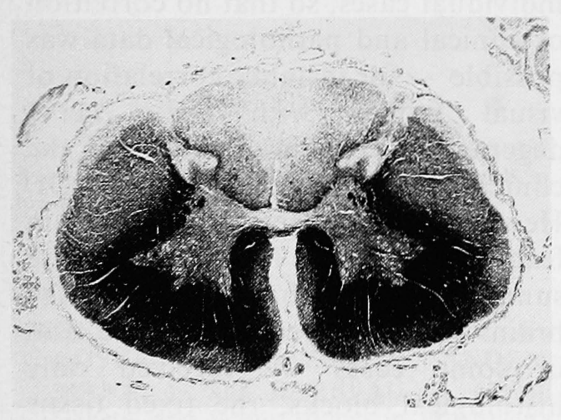

Figure 2-Upper medulla, showing shrinkage of pyramids and of ventral part of medial lemnisci. There is myelin loss in these structures, in the solitary tracts, and in parts of the inferior cerebellar peduncles. The olives are intact. Female: age at onset 9; age at death 22 .

appreciable in dorsal (cuneate) portion.

\section{Motor System}

Myelin pallor in pyramids in $13 / 15$ - moderate in 4 , mild in remainder. Traceable into pons in a few, but not into the cerebral peduncles. Loss and/or shrinkage of giant pyramidal cells in motor cortex in $11 / 11$. No lesions seen in cranial motor nuclei.

\section{Cerebellar Afferents (Fig. 2)}

Cell loss, cell shrinkage and gliosis in accessory cuneate nucleus in 15/15. Focal cell loss (? anoxic) in inferior olives in 5/15. No lesions in pontine nuclei or middle cerebellar peduncles.
Partial degeneration in inferior peduncle in all cases (vestibular: see below, 6).

\section{Cerebellar Cortex}

Patchy or focal drop-out of Purkinje cells (probably anoxic) in 15/15. Granule cells unaffected except by focal infarction. Stellate and basket cells: no changes seen.

\section{Cerebellar White Matter and}

Dentate Nuclei (Fig. 3)

Myelin staining normal, except for infarcts. Diffuse gliosis of white matter in most, probably all cases. Dentate nuclei: cell loss and gliosis in 13/15. Severe in 5, moderate in 8. Superior cerebellar peduncles degenerate in $13 / 15$, severely so in 6 . Tendency for more dorsal fibers to be relatively spared. In some cases, obvious shrinkage of tegmentum resulting from this.

\section{Vestibular System}

Myelin pallor of entering roots of vestibular nerves in $4 / 6$. Gliosis of vestibular nuclei: inferior $6 / 12$, medial $9 / 14$, lateral $6 / 11$, superior $5 / 9$. Cell loss hard to judge: seen in medial vestibular nucleus in several. Roof nuclei of cerebellum: gliosis in 4/5. Medial longitudinal bundle normal in $15 / 15$.

\section{Auditory System}

Myelin pallor of entering cochlear nerve in 5/7. Cell loss and gliosis of ventral cochlear nucleus in $5 / 9$. Cell loss and gliosis of dorsal cochlear nucleus in $4 / 8$. Cell loss and gliosis of superior olivary nucleus in 8/11. Gliosis without cell loss in inferior colliculus in 6/8. Myelin pallor of trapezoid body in $5 / 8$.

\section{Visual System}

Myelin pallor of optic tracts in $6 / 12$; severe in 2. Lateral geniculate bodies not systematically examined. Gliosis and partial cell loss noted in 2 .

\section{Basal Nuclei, etc. (Fig. 4)}

Substantia nigra normal in 13/13. Red nucleus gliotic in 6/11. Red nucleus cell loss in $3 / 11$. Subthalamic nucleus: partial cell loss and gliosis in 5/11. Pallidum; cell loss in external segment in 6/12. Internal segments normal in $9 / 9$. Striatum: normal (except for vascular lesions) in 13/13. Thalamus: local cell loss (? anoxic) in $5 / 13$. Central tegmental tract normal in $15 / 15$. Hypothalamus not systematically examined; no lesions seen.

\section{Cerebral Cortex and White Matter}

Not systematically examined, except for motor cortex. No

TABLE 1

Clinical Data on 13 of 15 Cases Examined*

\begin{tabular}{lrrrrrrrrrrrrr}
\hline Case & $\mathbf{1}$ & $\mathbf{2}$ & $\mathbf{3}$ & $\mathbf{4}$ & $\mathbf{5}$ & $\mathbf{6}$ & $\mathbf{7}$ & $\mathbf{8}$ & $\mathbf{9}$ & $\mathbf{1 0}$ & $\mathbf{1 1}$ & $\mathbf{1 2}$ & $\mathbf{1 3}$ \\
\hline Sex & $\mathrm{M}$ & $\mathrm{M}$ & $\mathrm{M}$ & $\mathrm{F}$ & $\mathrm{F}$ & $\mathrm{M}$ & $\mathrm{F}$ & $\mathrm{M}$ & $\mathrm{F}$ & $\mathrm{F}$ & $\mathrm{M}$ & $\mathrm{M}$ & $\mathrm{M}$ \\
Age at onset of ataxia & 6 & 7 & 8 & 9 & 9 & 10 & 10 & 10 & 12 & 12 & $13<$ & 19 & 20 \\
Age at death & 10 & 25 & 23 & 22 & 35 & 31 & 34 & 32 & 65 & 29 & 30 & 44 & 44 \\
Sibling(s) affected & 0 & + & 0 & 0 & 0 & + & 0 & + & + & + & 0 & 0 & 0 \\
Disability at death ** & $\mathrm{A}$ & $\mathrm{C}$ & $\mathrm{C}$ & $\mathrm{B}$ & $\mathrm{B}$ & $\mathrm{C}$ & $\mathrm{B}$ & $\mathrm{C}$ & $\mathrm{B}$ & $\mathrm{B}$ & $\mathrm{A}$ & $\mathrm{C}$ & $\mathrm{A}$ \\
Scoliosis & 0 & 0 & + & + & + & + & + & + & + & + & + & + & + \\
Pes Cavus & 0 & + & + & 0 & $?$ & + & 0 & + & + & $?$ & + & + & + \\
Dysarthria & + & + & + & + & $?$ & + & + & + & + & + & $?$ & $?$ & + \\
Visual disturbance & 0 & 0 & 0 & 0 & + & 0 & + & 0 & + & + & + & + & 0 \\
Deafness & 0 & 0 & 0 & 0 & + & + & + & $?$ & + & 0 & $?$ & $?$ & 0 \\
Diabetes Mellitus & 0 & 0 & + & 0 & + & 0 & 0 & + & + & + & 0 & $?$ & 0 \\
Abnormal ECG & + & + & + & + & + & + & + & + & $?$ & + & + & + & 0 \\
Heart failure & + & + & + & + & + & + & $?$ & + & $?$ & + & + & $?$ & 0 \\
\hline
\end{tabular}

* Clinical data on the other 2 cases lost. Both patients are said to have had 'classical' Friedreich's Ataxia

** $\mathrm{A}=$ Walking with assistance

$\mathrm{C}=$ Chairfast

$\mathrm{B}=$ Bedfast 
abnormalities seen apart from Betz cells and vascular lesions.

\section{DISCUSSION}

Although the figures given above are incomplete, and can no longer be checked, they are, as far as I know, the only available figures indicating the frequency of lesions at particular sites in "classical" Friedreich's ataxia. Previous histological reports have described single cases, or a small group of cases; and it is difficult to compare the reports of two histologists, or to know what is meant by each of them when he says, for instance, that there is "mild cell loss" in this or that nucleus.

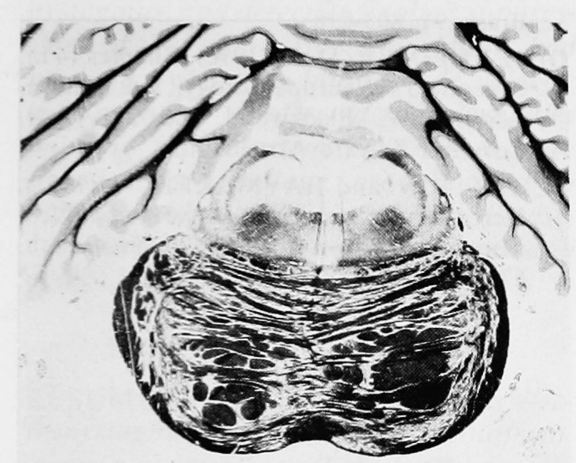

Figure 3-Pons, showing atrophy and pallor in the superior cerebellar peduncles. The cerebellar cortex, pontine nuclei, and transverse bundles are intact. Female: age at onset 10; age at death 34 .

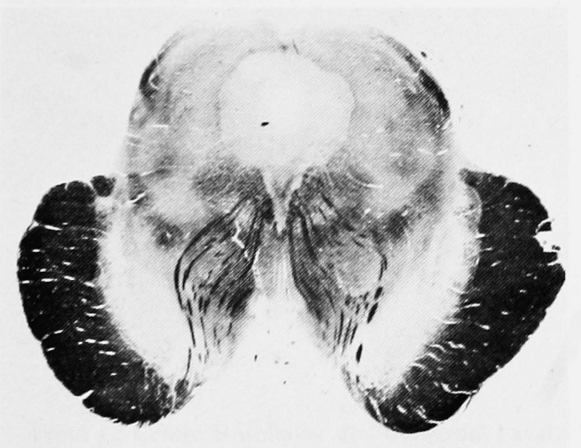

Figure 4-Midbrain, showing loss of myelin in and around the red nuclei, due to degeneration of superior cerebellar peduncles. Note absence of corticospinal tract degeneration. Male: age at onset 7 ; age at death 25 .
The criteria used in assessing these 15 cases, though they may be faulty, are at least consistent.

The overall impression is that the brain lesions in this disease are rather more variable than those in the spinal cord. The optic nerves, for instance, may be severely degenerated, or they may be intact. Other structures notably the accessory cuneate nuclei, which are for the upper limbs what the thoracic nuclei are for the lower limbs - were found to be severely affected in all cases. As for the primary sensory pathways, the findings in the brain confirm that the lesions are milder in the more rostral parts; the gracile component is always worse affected than the cuneate, and the cuneate lesions are in general worse than the trigeminal ones.

The lesions in the motor system showed interesting differences from those of motor neuron disease. Loss of anterior horn cells is a constant finding in motor neuron disease, but does not seem to occur in Friedreich's ataxia. 'Dying back' of the pyramical tracts is common, but not constant, in motor neuron disease (Brownell, Oppenheimer and Hughes, 1970); when it is severe in the spinal cord, it can almost always be traced upwards through the cerebral peduncles to the internal capsule and Rolandic cortex. In Friedreich's ataxia, on the contrary, the pyramidal tracts are always severely affected in the cord, are sometimes affected in the medulla, but seldom or never at the level of the cerebral peduncles. Changes in the motor cortex - in particular, loss of giant pyramidal cells in layer 5- have often been described in both conditions; but it remains uncertain whether these cells have actually died, or they are merely reduced in size conceivably as a result of atrophy of the distal parts of their axons.

As in other multisystem degenerations, it is hard to decide whether trans-synaptic, or 'chain', degeneration has occurred. In the present material, differences in the degree of degeneration of the gracile and cuneate contributions to the medial lemnisci suggest prograde transsynaptic degeneration in these two nuclei: but no such explanation can be given for the nearly constant cell loss in the dentate nuclei, in the presence of a normal population of Purkinje cells.

\section{TABLE 2}

Structures at Risk

\begin{tabular}{lcc}
\hline & $\begin{array}{c}\text { Friedreich's } \\
\text { Ataxia }\end{array}$ & $\begin{array}{c}\text { Multiple } \\
\text { System Atrophy }\end{array}$ \\
\hline Cerebral cortex & $(+)$ & $(+)$ \\
Striatum & + & + \\
Pallidum & + & ++ \\
Subthalamic nuclei & - & + \\
Pigmented nuclei & - & + \\
Pontine nuclei & $(+)$ & + \\
Inferior olives & + & + \\
Cochlear nuclei and superior olives & + & + \\
Vestibular nuclei & - & + \\
Cerebellar Purkinje cells & - & + \\
Cerebellar granule cells & ++ & + \\
Dentate nuclei & ++ & + \\
Thoracic and access. cuneate nuclei & - & + \\
Intermediolateral columns & - & + \\
Motor nuclei & ++ & + \\
Sensory ganglia & + & + \\
\hline Optic nerves & ++ & + \\
Pyramidal tracts (“dying back”) & & +
\end{tabular}

++ always or nearly always affected

+ commonly affected

$(+)$ occasionally affected

- seldom if ever affected

Cerebral cortex

Subthalamic nuclei

Pontine nuclei

Inferior olives

Vestibular nuclei

Cerebellar Purkinje cells

Dentate nuclei

Thoracic and access. cuneate nuclei 
Previous reports have described loss of Purkinje cells and of olivary cells in Friedreich's ataxia. In the present material, vascular lesions were common. Many of these were welldefined infarcts, and were readily attributable to emboli from the heart due to auricular fibrillation. Patchy and inconstant loss of nerve cells in the cerebral cortex, hippocampus, thalamus, striatum, inferior olives and cerebellar cortex seemed to be more readily attributable to hypoxia resulting, for instance, from episodes of heart failure, than to the primary disease; but this could not be regarded as certain. It is also possible that cardiovascular troubles are responsible for the dementia which is occasionally a feature of Friedreich's disease.

Some authors regard all forms of hereditary cerebellar and spinocerebellar degenerations as parts of a continuous spectrum. Certainly, there are cases, sometimes diagnosed as atypical Friedreich's, in which some, but not all, of the features of the 'classical' disease are present; and there are families such as the one described by Schut and Haymaker (1951), in which a single, presumably dominant, gene produces a great variety of clinical disturbances, with corresponding pathological changes, in some cases resembling Friedreich's disease and in others ponto-cerebellar atrophy.

In general, however, a reasonably clear line can be drawn between classical Friedreich's disease and the kind of multiple system atrophy which includes ponto-cerebellar atrophy and striato-nigral degeneration (Oppenheimer, 1976). Not only are there striking clinical differences - for instance, absence of visceral disturbances in the latter condition, and a difference of 30 to 50 years in the usual age of onset - but there is very little overlap in the nervous structures which are at risk in the two conditions, as can be seen from Table 2 .

\section{ACKNOWLEDGEMENTS}

I am indebted to Drs. Betty Brownell, Richard L. Hewer, and J. Trevor Hughes, who collected most of the material on which this report is based.

Editor's Note: This paper, and the collaboration of Dr. Oppenheimer, was specifically requested so that a permanent record of this unique, if incomplete, material be made available to all those interested in Friedreich's ataxia, despite the loss of some information due to a fire.

\section{REFERENCES}

BROWNELL, B., OPPENHEIMER, D. R. and HUGHES, J. T. (1970). The central nervous system in motor neurone disease. J. Neurol. Neurosurg. Psychiat., 33: 338-357.

HUGHES, J. T., BROWNELL, B. and HEWER, R. L. (1968). The peripheral sensory pathway in Friedreich's ataxia. Brain, 91: 803-818.

OPPENHEIMER, D. R. (1976). Chapter 14 in: Greenfield's Neuropathology, 3rd Edition. Editors: W. Blackwood and J. A. N. Corsellis. Edward Arnold Ltd.

SCHUT, J. W. and HAYMAKER, W. (1951). Hereditary ataxia: a pathologic study of five cases of common ancestry. J. Neuropath. Clin. Neurol. 1: 183-213. 